\title{
Bibliometric analysis of productivity and keyword trends in articles on physical therapy and ageing (1990-2014)
}

\author{
DOI: https://doi.org/10.5114/pq.2020.100287
}

\author{
Anna Arnal-Gómez', Carolina Navarro-Molina², Gemma V. Espí-López ${ }^{1}$ \\ ${ }^{1}$ Department of Physiotherapy, Faculty of Physiotherapy, University of Valencia, Valencia, Spain \\ ${ }^{2}$ Superior Council of Scientific Investigations, Institute of Agrochemistry and Food Technology, Paterna (Valencia), Spain
}

Abstract

Introduction. The increase in population longevity has led the subject of ageing to take an important role in research and innovation policies. Considerable efforts have been made worldwide to promote research on physiotherapy and ageing. Therefore, applying bibliometric measures can be useful to identify emerging and innovative scientific indicators. This study identifies productivity and topic trends in physiotherapy in ageing and the main publishing authors, institutions, and countries.

Methods. A bibliometric analysis was applied in original articles published on the Science Citation Index Expanded of Web of Science Core Collection (1990-2014). Bibliometric indicators were obtained by using specific bibliometric software. Pearsons' correlation coefficient $(r)$ was applied for correlations; statistical significance was considered for $p<0.01$.

Results. Overall, 2237 original articles were included. Topic trends show an initial focus on illness and evolve towards the study of prevention. Authors and institutions increased productivity and citation. The most productive country was the United States, and there was a significant correlation between productivity and gross domestic product $(p<0.01)$. No statistically significant relationship was observed between productivity and the countries' aged population.

Conclusions. Productivity increased, with a greater scientific interest in prevention. The published research was mainly related to wealthy and developed countries.

Key words: bibliometrics, physical therapy modalities, ageing, trends

\section{Introduction}

Worldwide, the number of older adults is expected to more than double by 2050 and more than triple by 2100 , with most of the increase in developing countries [1]. Global statistics show that Japan leads the ranking of countries with the highest proportion of the population over 65 years of age (26.3\%), followed by European countries: Italy (22.4\%), Germany (21.2\%), France (19.1\%), Spain (18.8\%), and the United Kingdom (17.8\%). However, other countries, such as the United States (14.8\%), reveal a much younger age structure than that of Europe. Developing countries show low percentages of population aged over 65 years, e.g. $7.8 \%$ in Brazil and $2.7 \%$ in Nigeria [2].

According to the World Health Organization, these data of populations' ageing can be considered a success of public health policies and socioeconomic development [3]. However, ageing has become a challenge to health professions such as physiotherapy (PT) specialists since it involves a gradual reduction in the capacity to adapt and an increase in vulnerability to health issues such as chronic non-communicable diseases and musculoskeletal disorders [4]. On the other hand, there are elder people who enjoy successful ageing, which implies not suffering from chronic diseases and having optimal social engagement and mental health, as well as no physical disability [5]. Moreover, healthy ageing [6] or successful ageing is a multi-domain concept that comprises and transcends good health, and it is made up of a wide spectrum of biopsychosocial factors [7]. Therefore, PT and other health professions play a fundamental part not only in illness, but also in maintaining or improving functionality throughout the cycle of life [8] in order to prevent decreases in quality of life whenever the changes of old age start to appear [9].

Some previous bibliometric studies have already described PT research from different perspectives [10,11]. One of the first PT bibliometric studies analysed citations of the Physical Therapy and Physiotherapy Canada journals between 1981 and 1982, concluding that the 5 authors who were considered as 'eminent' in the profession appeared regularly as highly cited in both journals [12]. In the same year, Bohannon and Gibson [13] published their citation analysis of journals cited in Physical Therapy, finding that Physical Therapy and Archives of Physical Medicine and Rehabilitation were the most cited.

Some authors have analysed the quality of PT research [10, 14-16]. In 1991, a citation analysis conducted by Bohannon and Roberts [17] helped to establish a 'core list' of rehabilitation journals. The authors concluded that information regarding rehabilitation was being published by a large number of different journals. Tesio et al. [18] found that rehabilitation scientific literature comprised a relatively small number of published articles, with a greater proportion of them published in journals with no impact factor (IF).

In 2001, another bibliometric study analysed IF in rehabilitation journals [19]. In the same year, Maher et al. [15] conducted a study on journals indexed in the Physiotherapy Evidence Database (PEDro) and compared their contents with previously published articles. Later, in 2004, they performed another bibliometric study in order to analyse the quality of scientific evidence in PT [20].

Correspondence address: Gemma Victoria Espí-López, Department of Physiotherapy, Faculty of Physiotherapy, University of Valencia, Gascó Oliag Street, 5, 46010 Valencia, Spain, e-mail: gemma.espi@uv.es 
In 2011, 2 bibliometric studies analysed content trends and themes of 2 journals: Journal of Orthopaedic \& Sports Physical Therapy [21] and Physical Therapy [22]. In 2012, the latter journal was investigated with both traditional bibliometric indicators (such as citation) and more novel ones (as quantitative and collaborative indicators) to track trends in authors, productivity, and consumption of research from 1945 to 2010 [23].

PT bibliometric studies were also centred on specific areas. Svien et al. [24] reviewed 15 years of research in the field of paediatric PT. Hoffmann et al. [25] studied strokerelated interventions in the OTseeker database in terms of research evidence quantity, quality, and content.

PT publications, in spite of being a relatively new phenomenon in the scientific literature [26, 27], have undergone a considerable development worldwide and the theme of ageing has taken a prominent role owing to the increase in the population's longevity [28]. When dealing with a complex phenomenon such as ageing, it is very useful to apply bibliometric measures to identify emerging and innovative topics, anticipate advances, and determine which paradigms will dominate research in the future [29, 30]. Bibliometric research has already been implemented in most scientific fields [31, 32], and it can allow researchers and professionals of PT in ageing to analyse publications and identify future research opportunities [33].

The purpose of this study was to use bibliometric indicators to identify the productivity, evolution, and advances of topics within PT in ageing. Our study also reveals the main authors, institutions, and countries of the area, as well as their impact, in order to encourage communication among researchers and ultimately contribute to the building of the knowledge base in the field. Describing the publication patterns of PT in ageing over 25 years helps make inferences about the emerging and innovative themes, as well as the evolution of the profession in a worldwide perspective, and therefore offer clinicians and researchers a better understanding of the scientific literature.

\section{Subjects and methods}

\section{Database selection}

The Web of Science (WoS) database was searched to retrieve original articles related to PT in ageing published from 1900 to 2014 in order to conduct a bibliometric study. WoS is an international multidisciplinary tool which includes all scientific and technological areas and presents a detailed citation analysis [34]. More specifically, the Science Citation Index Expanded (SCl-E) of WoS Core Collection was selected, as in previous studies [35, 36].

\section{Search strategy}

The search strategy was based on terms related to PT, physical therapist, ageing, and PT techniques in ageing. The terms were selected owing to their presence in the Medical Subject Headings (MeSH) thesaurus [37] or in previous bibliometric studies [21-23, 38-40], or they were professional terms of PT $[8,41]$. The final search strategy had $115 \mathrm{com}-$ bined terms (Appendix 1).

As for the limits, the time limit was initially from 1900 to 2014 but finally started with 1990, the year of the first result. The articles type of document was selected, since original articles of scientific journals with peer review are the most appropriate for bibliometric studies [31]. All categories of SCI-E were selected in order to obtain the multidisciplinary view that the ageing process requires. No language limits were applied. The literature search was performed in July 2015 and a total of 2417 documents were retrieved.

\section{Standardization of the bibliographic information}

After manually removing 180 non-pertinent references, the bibliographic information from the 2237 finally selected documents was downloaded to a specific bibliometric relational database (Bibliométricos.mdb) in a Microsoft Access file. This information was then subjected to a standardization process to bring together the different names of a particular author, institution, or keyword.

The authors' signatures were standardized because sometimes an author appears as 2 or more signatures. This is due to authors' using only 1 surname or 2 , or only 1 first name or more, as well as because graphic signs, such as hyphens, are applied to separate names, and there are variations in the indexing process (e.g. the standardized author Abbott, J Haxby had the variants of Abbott, J. H.; Abbott, J. Haxby; and Abbott, J.).

In relation to institutions, the different variants of university or hospital names were unified. Some institutional signatures collected 2 or more institutions, like university hospitals and universities. With the aim of not losing information, these signatures were differentiated in order to indicate, for each bibliographic record, as many macro-institution signatures as could be identified.

Keywords were standardized with the consideration of the World Confederation for Physical Therapy (WCPT) glossary [41], Medline Plus dictionary of the United States National Library of Medicine, and MeSH thesaurus [37].

\section{Analysis of the scientific production}

A series of global bibliometric indicators were obtained. The first ones were the number of articles and productivity distribution through quinquennia. Secondly, in relation to the topics, the occurrence of the keywords and their distribution over quinquennia were calculated. Regarding the graphic representation of the links between keywords, the existence of a link was considered when 2 or more keywords were used together in at least: 2 articles ( $1^{\text {st }}$ quinquennium), 4 articles ( $2^{\text {nd }}$ quinquennium), 10 articles ( $3^{\text {rd }}$ quinquennium), 20 articles ( $4^{\text {th }}$ quinquennium), and 35 articles ( $5^{\text {th }}$ quinquennium). For the graphic representation of the links, the Pajek network analysis program was used.

Thirdly, regarding authors, the following bibliometric indicators were calculated: number of authors, citation of the authors, and Lotka's productivity index (PI) [42]. PI allows to identify highly productive authors, who are those with 10 or more published papers $(\mathrm{PI} \geq 1)$; medium producers, with 2-9 published papers $(0<\mathrm{PI}<1)$; and small producers, with only 1 article $(\mathrm{PI}=0)$. The citation for each quinquennium and the $h$-index [43] of the highly productive authors were identified. The $h$-index is the result of the combination of productivity and citation given in an index: an author has an $h$-index if all of their $h$ articles receive at least $h$ citations each and the rest have at most $h$ citations [44].

Finally, the same methodology was applied to analyse the institutional signatures and the countries productivity, identifying citations and PI for the institutions and countries. 


\section{Statistical analysis}

Descriptive results for continuous data were expressed as mean and standard deviation, while nominal data were described as frequencies and percentages. In order to identify the level of statistically significant correlations between productivity and citation, Pearsons' correlation coefficient $(r)$ and the coefficient of determination $\left(r^{2}\right)$ were applied for correlations between productivity and citation. Statistical significance was considered for $p<0.01$. Coefficient determination $\left(r^{2}\right)$ was reported as a measure of exposure influence on outcome variability. The same methodology was applied to analyse the correlation between productivity and countries' aged population, and productivity and the gross domestic product (GDP) of the countries in order to offer a broader view of scientific activity associated with sociodemographic and economic indicators, respectively, and therefore be able to explain imbalances of resources allocated to research which may be caused by population or wealth differences.

\section{Ethical approval}

The conducted research is not related to either human or animal use.

\section{Results}

\section{Articles productivity and topic trends}

The number of analysed articles was 2237 , with an average of $447.4(S D=406.98)$ articles per quinquennium (Figure 1). Between the $1^{\text {st }}$ quinquennium and the last one, publications increased by $45.33 \%$ (1014 articles), with an average growth between quinquennia of $9.70 \%$ (217 articles).
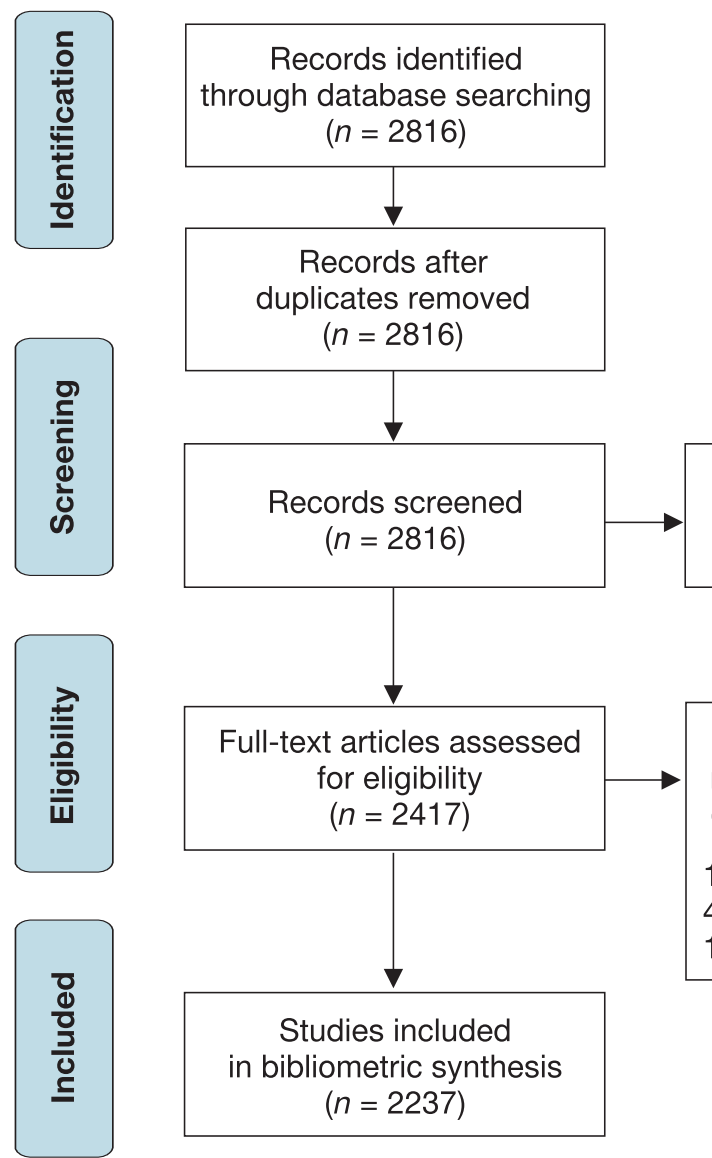

Records excluded $(n=399)$ $(n=180)$ :
In relation to the topics, the 2237 analysed articles used 3396 different keywords, with the following ones being the most frequent during the whole studied period: physical therapy (45.69\%), older people (31.96\%), rehabilitation (26.96\%), clinical trial (24.05\%), and exercise (23.60\%).

In addition, the co-occurrence links between highly used keywords were analysed for each quinquennium: (a) In the $1^{\text {st }}$ period (1990-1994), the keywords that were used together in a greater number of articles were: physical therapy and pain (8.5\%), followed by physical therapy and rehabilitation (7\%) (Figure 2). (b) In the $2^{\text {nd }}$ quinquennium (1995-1999), the previous links were consolidated and there was an outstanding increase in the association of physical therapy and clinical trial (6.8\%). On the whole, in the first 2 quinquennia, there were prominent associations of keywords related to pathologies such as hemiplegia, chronic bronchitis, cystic fibrosis, or heart disease, which did not appear in the following quinquennia. (c) In the $3^{\text {rd }}$ quinquennium (2000-2004), there was a highlighted increase in the association of physical therapy and exercise (from $5.6 \%$ in the $1^{\text {st }}$ quinquennium to $14.52 \%$ in the $3^{\text {rd }}$ one). Moreover, the keywords physical therapy and quality of life appeared for the first time as a prominent association, which increased and consolidated in the following periods. In fact, the keyword quality of life presents an increased percentage from the $1^{\text {st }}$ to the last quinquennium of $63.03 \%$. (d) In the period 2005-2009, associations were consolidated between physical therapy and: clinical trial (18\%), exercise (15\%), and rehabilitation (14.6\%). (e) In the last quinquennium (Figure 3), there was still an outstanding association between physical therapy and rehabilitation (16.22\%), followed by physical therapy and clinical trial (15.29\%) and physical therapy and exercise (15.20\%). On the whole, in the last 3 quinquennia, some keywords such as exercise, physical activity, prevention, health care, exercise therapy, risk factor, or quality of life had a highlighted position; however, they were not so significant in the first 10 years.

Globally, the graphic representation of the keyword links in the $1^{\text {st }}$ and last quinquennium (Figures 2 and 3 ) shows the increase in productivity, since the thickness of both vertices and edges, which represent the number of articles, increased in an outstanding way.
Full-text articles excluded for non-pertinent references

121 for not being related to ageing 43 for not being related to physiotherapy topics 16 for not being original publications 


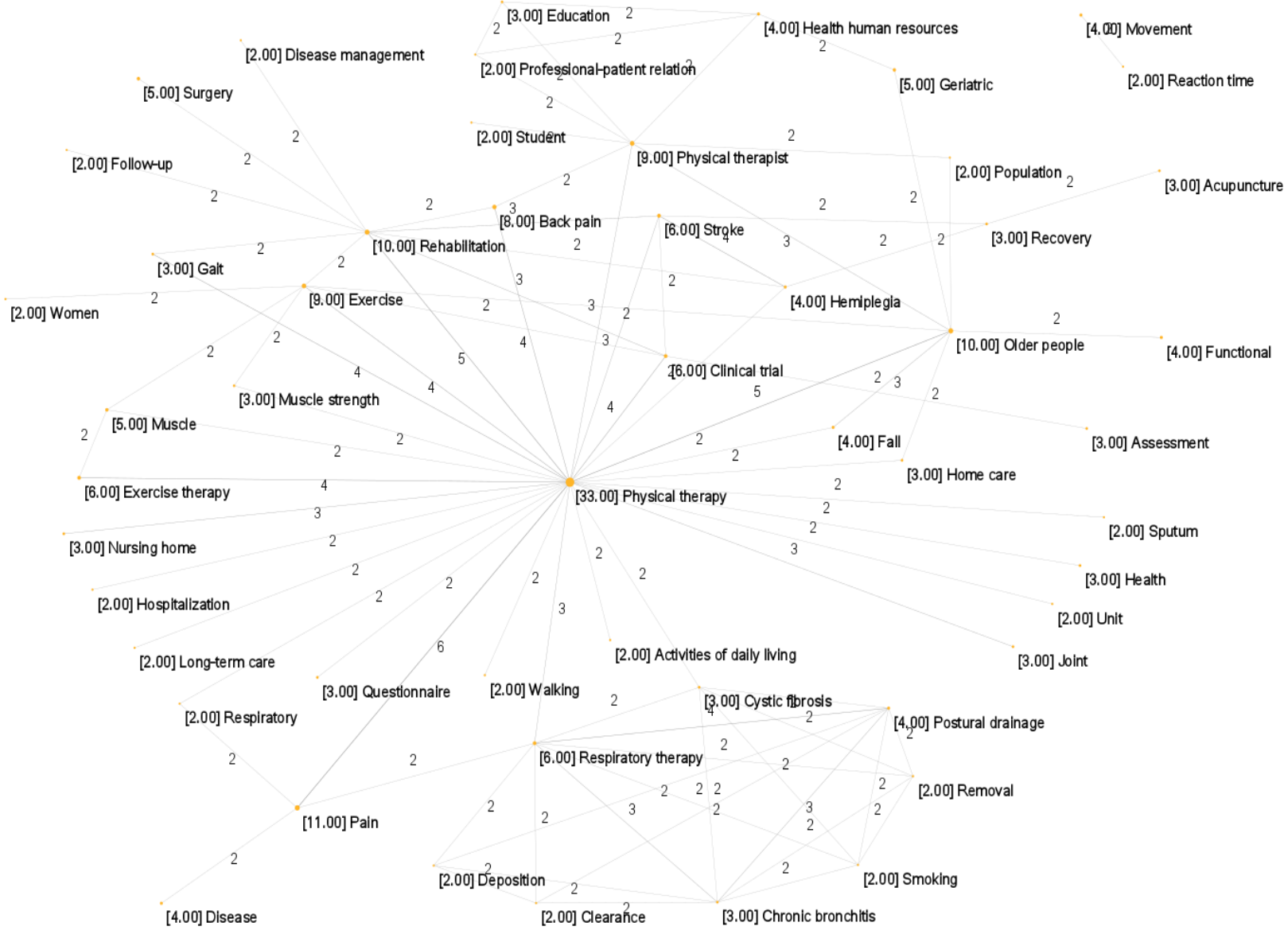

The size and the numeric label of a node represent the number of articles that studied each keyword.

The thickness and the numeric label of a line represent the number of articles that studied the 2 linked keywords.

Figure 2. Graphic representation of the co-occurrence of keywords in the $1^{\text {st }}$ quinquennium, 1990-1994 (> 2 articles)

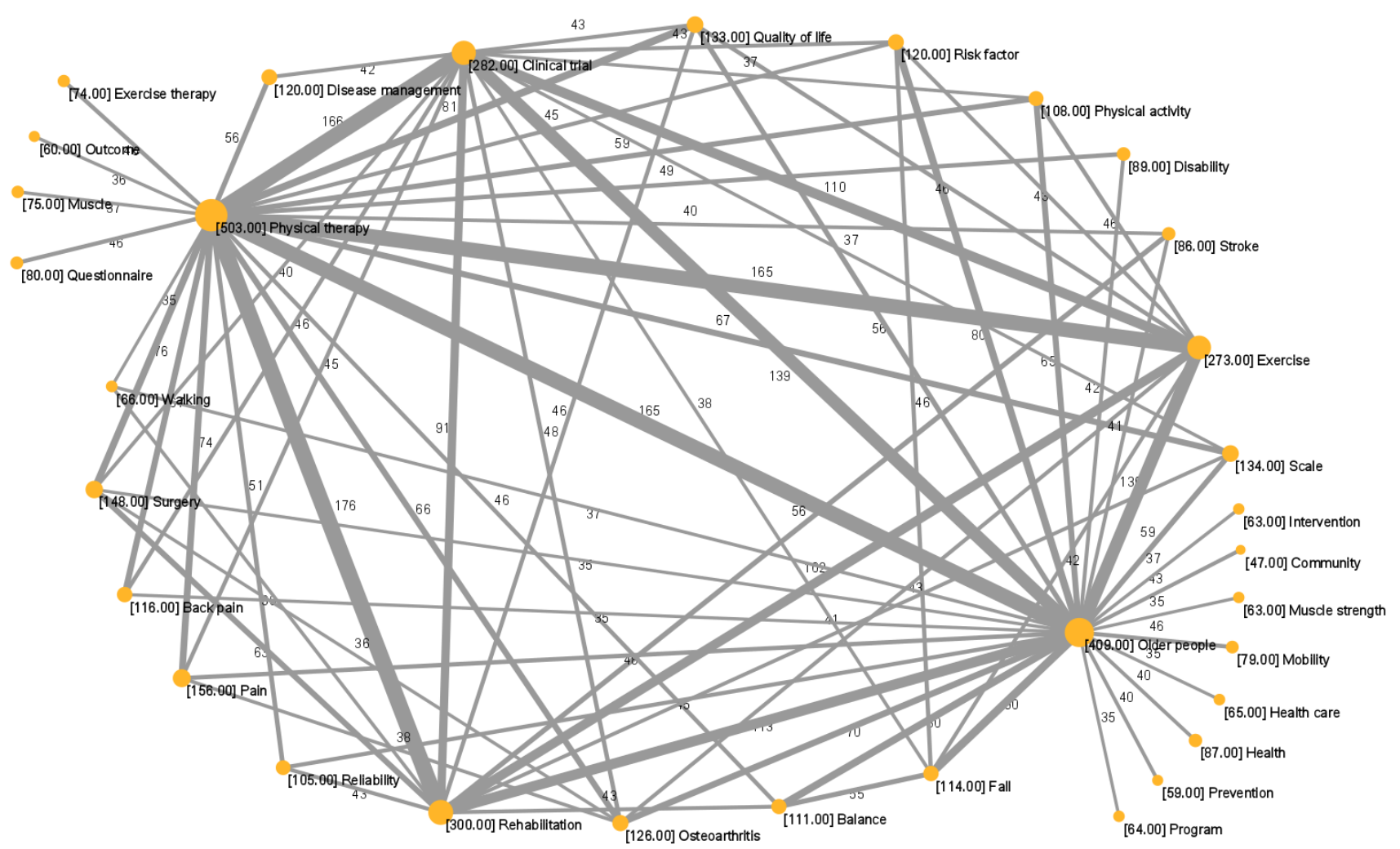

The size and the numeric label of a node represent the number of articles that studied each keyword.

The thickness and the numeric label of a line represent the number of articles that studied the 2 linked keywords.

Figure 3. Graphic representation of the co-occurrence of keywords in the last quinquennium, 2010-2014 (> 35 articles) 
Table 1. Quinquennium distribution of publications and citations, and the $h$-index of highly productive authors

\begin{tabular}{|c|c|c|c|c|c|c|c|c|c|c|c|c|c|}
\hline \multirow{2}{*}{ Authors* } & \multicolumn{2}{|c|}{ 1990-1994 } & \multicolumn{2}{|c|}{ 1995-1999 } & \multicolumn{2}{|c|}{ 2000-2004 } & \multicolumn{2}{|c|}{ 2005-2009 } & \multicolumn{2}{|c|}{ 2010-2014 } & \multicolumn{2}{|c|}{ Total } & \multirow{2}{*}{$h$-index } \\
\hline & $\mathrm{P}$ & C & $P$ & C & $P$ & $\mathrm{C}$ & $P$ & C & $P$ & C & $\mathrm{P}$ & C & \\
\hline Fritz JM & 0 & - & 0 & - & 3 & 480 & 15 & 795 & 5 & 30 & 23 & 1305 & 25 \\
\hline Cleland JA & 0 & - & 0 & - & 0 & - & 11 & 294 & 8 & 76 & 19 & 370 & 29 \\
\hline Hay EM & 0 & - & 0 & - & 1 & 9 & 11 & 431 & 6 & 49 & 18 & 489 & 20 \\
\hline Lord SR & 0 & - & 2 & 108 & 4 & 692 & 2 & 104 & 8 & 49 & 16 & 953 & 35 \\
\hline Bennell KL & 0 & - & 0 & - & 1 & 49 & 2 & 41 & 11 & 95 & 14 & 185 & 27 \\
\hline Sherrington C & 0 & - & 2 & 108 & 2 & 94 & 3 & 118 & 6 & 42 & 13 & 362 & 24 \\
\hline Brennan GP & 0 & - & 0 & - & 0 & - & 8 & 404 & 4 & 18 & 12 & 422 & 13 \\
\hline De Bie RA & 0 & - & 0 & - & 1 & 29 & 4 & 48 & 7 & 78 & 12 & 155 & 21 \\
\hline Foster NE & 0 & - & 0 & - & 1 & 9 & 6 & 211 & 5 & 26 & 12 & 246 & 23 \\
\hline Morris ME & 0 & - & 1 & 95 & 4 & 175 & 3 & 24 & 4 & 61 & 12 & 355 & 22 \\
\hline Haines TP & 0 & - & 0 & - & 0 & - & 5 & 87 & 5 & 37 & 10 & 124 & 2 \\
\hline Hill KD & 0 & - & 0 & - & 1 & 38 & 1 & 7 & 8 & 84 & 10 & 129 & 19 \\
\hline Vicenzino B & 0 & - & 1 & 123 & 1 & 73 & 4 & 207 & 4 & 74 & 10 & 477 & 35 \\
\hline Whitman JM & 0 & - & 0 & - & 2 & 54 & 6 & 210 & 2 & 12 & 10 & 276 & 17 \\
\hline
\end{tabular}

$\mathrm{P}$ - number of publications, $\mathrm{C}$ - number of citations

${ }^{*}$ Authors are shown by productivity order.

\section{Main authors and their impact}

A total of 8486 authors were identified and accumulated 10,582 signatures. The number of publishing authors increased from 263 in 1990-1994 to 4716 in 2010-2014. The average number of signatures per article also increased: from $4.07(S D=1.14)$ in the first 5 years to $5.14(S D=0.34)$ in the last period.

$\mathrm{PI}$ allowed us to identify the number of authors for each productivity level: $14(0.16 \%)$ were high producers, 1157 (13.63\%) were medium producers, and 7315 (86.20\%) were low producers. High producers (Table 1) published 191 articles $(8.54 \%$ of the total number), with the most productive author being Fritz JM from University of Utah (United States), followed by Cleland JA of Franklin Pierce University (United States) and Hay EM from Keele University (United Kingdom).

For high producers, the most productive period was 2010 2014 (43.46\% of publications), followed by 2005-2009 (42.40\%). Only 4 authors published in 4 consecutive quinquennia: Lord SR, Sherrington C, Morris ME, and Vicenzino B, all affiliated to Australian universities.

Regarding citation, they accumulated a total of 5848 citations in 191 articles, with an average of 28.77 citations per article. Fritz JM, the most productive author, was also the most cited; she began to publish in this area in the period 2000-2004, and with only 3 articles she received 480 citations. This phenomenon was also observed with other authors, such as Lord SR, Sherrington C, Morris ME, and Vicenzino $\mathrm{B}$, who, with their first publications in the $2^{\text {nd }}$ or $3^{\text {rd }}$ quinquennium, despite a reduction (1 to 4 articles), received more than 100 citations. As for the h-index, all the highly productive authors exhibited a value above 10, except Haines TP.

Pearson's coefficient showed a positive and low correlation, although significant $\left(r=0.38, p<0.01, r^{2}=0.14\right)$, between authors' productivity and citation.
Institutions productivity and impact

A total of 2164 institutions were identified from 63 different countries and they accumulated a total of 5156 institutional signatures. The number of publishing institutions increased from 97 (1990-1994) to 2046 (2010-2014). In 38.31\% of the articles, only a single institution signed, while in $53.24 \%$, 2,3 , or 4 institutions collaborated in the same article. Only in $8.45 \%$ of the cases, $5-17$ institutions collaborated.

The PI of the institutions revealed 79 (3.65\%) high producers, 651 (30.08\%) medium producers, and 1434 (66.27\%) small producers. The 5 most productive institutions were: the University of Sydney, University of Queensland, University of Melbourne, University of Washington, and University of Toronto; all of them increased the publications in the 25 studied years (Figure 4).

With regard to citation, a total of 116,183 cites distributed in 1826 institutions (84.38\%) were accumulated. The most cited institution was the University of Pittsburgh (United States), with 2140 citations, followed by Lund University (Sweden), with 1994 citations, and University of Washington (United States), with 1336 citations. The 5 most productive institutions were among the 20 most cited ones.

Pearson's coefficient showed a high and significant positive correlation between institutions' productivity and their citation $\left(r=0.73, p<0.01, r^{2}=0.53\right)$.

\section{Country productivity and impact}

A total of 63 different countries were identified and accumulated 2584 signatures. The number of countries increased by an average of $17.86 \%(S D=18.66)$, from 18 in $1990-1994$ to 63 in 2010-2014.

There were $30(47.62 \%)$ highly productive countries $(\mathrm{PI} \geq 1), 20(31.75 \%)$ medium producers $(0<\mathrm{PI}<1)$, and $13(20.63 \%)$ small producers $(\mathrm{PI}=0)$. The 5 most productive countries were the United States (621 publications), the 

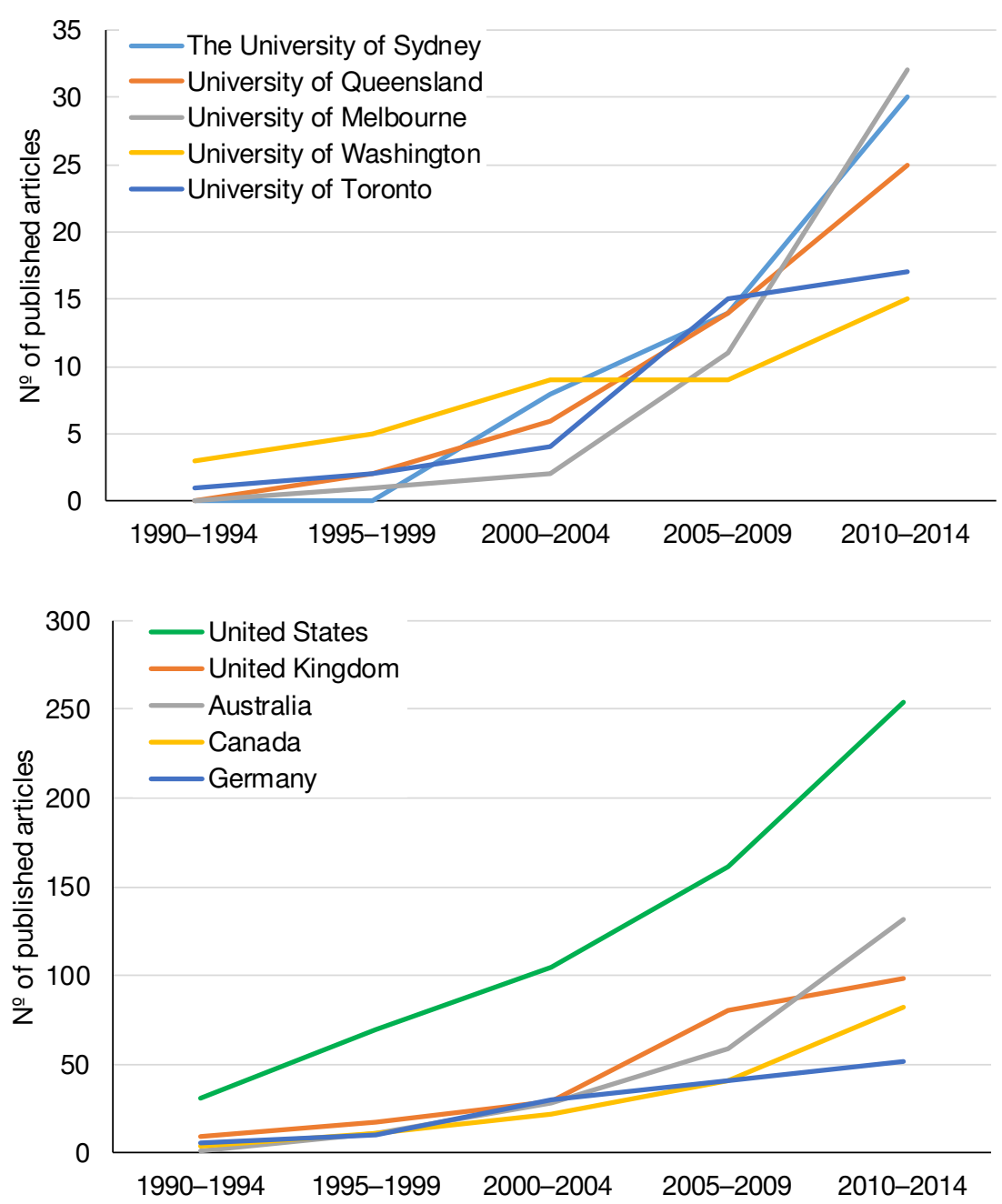

Figure 4. Evolution of publications of the 5 most productive institutions in the 25 studied years
Figure 5. Evolution of publications of the 5 most productive countries in the 25 studied years
United Kingdom (233), Australia (231), Canada (160), and Germany (139). The productivity evolution of these 5 countries showed that in the $1^{\text {st }}$ quinquennium, they published less than 35 articles, while in the last one, they all exceed 50 publications, with the United States even reaching 250 (Figure 5). Among these 5 countries, Australia experienced the highest percentage growth through the 25 studied years (56.70\%).

In the highly productive countries, productivity related to the ageing of their population (Table 2) shows Sweden in first position, followed by Australia, Denmark, Norway, and Israel. The correlation between productivity and aged population was positive but very low and not significant $(r=0.01$, $p>0.01, r^{2}=0.00$ ).

Productivity as related to GDP was also led by Sweden, followed by Australia, New Zealand, Finland, and the Netherlands. The correlation between productivity and GDP was positive, high, and significant $\left(r=0.70, p<0.01, r^{2}=0.48\right)$.

The 30 most productive countries accumulated a total of 58,958 citations, with the 3 most productive countries also being the most cited, in the same order. In fact, the correlation between productivity and country citation was positive and very high, almost perfect, and significant $(r=0.97, p<$ $\left.0.01, r^{2}=0.94\right)$.

\section{Discussion}

The present bibliometric study allowed us to obtain a scientific description of PT research in ageing worldwide during the period 1990-2014. Interesting data have been obtained ticles focused on pathology to more recent studies concentrated on prevention. Quantitative and qualitative data of the activity of researchers and institutions have also been obtained, revealing an increase in production and citation in both cases, with positive and significant correlations between these aspects. Finally, it has been found that the United States had the lead in terms of absolute productivity and citation, followed by other developed countries, such as the United Kingdom and Australia.

To our best knowledge, this is the first study to analyse bibliometric data of PT in ageing. Although there is currently a growing interest in this subject, there are still few bibliometric studies that focused on PT $[10,11]$, and none of them analysed the specialty of ageing. In addition, not many PT bibliometric studies have investigated trends during periods of at least 25 years [10,14-16] or have analysed more than 2000 PT articles [14, 45-47]. Moreover, few studies have used keywords analysis in order to determine associations of the topics $[23,48]$.

Bibliometric analysis allows to examine scientific literature and describe publication trends [49-51]. Previous studies show an increase of publications on ageing in WoS, from 2300 articles in 1989 to 16,000 in 2009 and to more than 56.000 in $2015[52,53]$. Our study provides data on the increase in publications related to PT in ageing, as well as the productivity increase per quinquennia. For authors, institutions, and countries, this increase was more evident from the 2000-2004 quinquennium onwards, which concurs with the beginning in 2002 of the 'Research agenda on aging for the $21^{\text {st }}$ century' of the International Association of Gerontology 
Table 2. Highly productive countries' productivity in relation to number of inhabitants older than 60 years and GDP

\begin{tabular}{|c|c|c|c|c|c|}
\hline Country* & No. of articles & $\begin{array}{l}\text { Millions of people } \\
\text { aged } 60 \text { or more }{ }^{\star *}\end{array}$ & $\begin{array}{l}\text { Articles per million people } \\
\text { aged } 60 \text { or more }\end{array}$ & $\begin{array}{l}\text { Position: articles/aged } \\
\text { population }\end{array}$ & GDP $2018^{* \star *}$ \\
\hline United States & 621 & 66 & 9.41 & 16 & 20412 \\
\hline United Kingdom & 233 & 15 & 15.53 & 12 & 2936 \\
\hline Australia & 231 & 5 & 46.20 & 2 & 1500 \\
\hline Canada & 160 & 8 & 20 & 10 & 1798 \\
\hline Germany & 139 & 22 & 6.32 & 17 & 4211 \\
\hline Brazil & 137 & 24 & 5.71 & 18 & 2138 \\
\hline Netherlands & 115 & 4 & 28.75 & 7 & 945 \\
\hline Sweden & 105 & 2 & 52.50 & 1 & 600 \\
\hline Turkey & 87 & 9 & 9.67 & 15 & 909 \\
\hline Italy & 63 & 17 & 3.71 & 21 & 2181 \\
\hline France & 59 & 16 & 3.69 & 22 & 2925 \\
\hline Switzerland & 52 & 2 & 26 & 8 & 741 \\
\hline Spain & 47 & 11 & 4.27 & 20 & 1506 \\
\hline Denmark & 43 & 1 & 43 & 3 & 369 \\
\hline Belgium & 42 & 3 & 14 & 13 & 562 \\
\hline Japan & 39 & 42 & 0.93 & 29 & 5167 \\
\hline Norway & 36 & 1 & 36 & 4 & 443 \\
\hline Finland & 36 & 2 & 18 & 11 & 289 \\
\hline Israel & 31 & 1 & 31 & 5 & 373 \\
\hline New Zealand & 29 & 1 & 29 & 6 & 220 \\
\hline Poland & 28 & 9 & 3.11 & 23 & 614 \\
\hline Ireland & 24 & 1 & 24 & 9 & 385 \\
\hline China & 24 & 209 & 0.11 & 28 & 14092 \\
\hline Taiwan & 23 & 209 & 0.11 & 28 & 613 \\
\hline South Korea & 21 & 9 & 2.33 & 24 & 1693 \\
\hline Austria & 21 & 2 & 10.50 & 14 & 477 \\
\hline Iran & 12 & 7 & 1.71 & 25 & 418 \\
\hline Thailand & 12 & 11 & 1.09 & 26 & 483 \\
\hline India & 11 & 117 & 0.09 & 27 & 2848 \\
\hline Saudi Arabia & 10 & 2 & 5 & 19 & 748 \\
\hline
\end{tabular}

GDP - gross domestic product

${ }^{*}$ Countries are shown by productivity order.

** Source: Global Age Watch Index 2015. Available from: http://www.helpage.org/global-agewatch/ [20.11.2016]

*** Source: International Monetary Fund. World Economic Outlook database. Available from: http://www.imf.org/external/pubs/ft/ weo/2015/01/weodata/index.aspx [20.11.2016]

and Geriatrics and the United Nations Programme on Aging of 2007 [54]. Therefore, the productivity trends show that the agenda was a unique initiative worldwide, which contributed to the direction and priorities of scientific gerontology [53].

Moreover, this continuous increase of research in PT in ageing has important implications at both clinical and academic levels, since it facilitates decision making concerning the treatment of patients [10]. Precisely, our results indicate a change in the paradigm of the scientific study of the treatment of ageing. The keyword bibliometric analysis in the $1^{\text {st }}$ quinquennia showed words related with chronic diseases and disability among the elderly. Therefore, much of the initial focus was on the determinants of mortality, illness, and disability, as observed with other health professions [55]. However, the fact that elder people may have a successful ageing has transformed the study of ageing from a discipline concentrated on disease and decline to one emphasizing health and growth [56]. This is in line with recent studies analysing the need for medical and nonmedical services among the elderly through FIMA, a questionnaire for health-related 
resource use $[57,58]$. Standardized instruments like the FIMA questionnaire plus the results of the present study, which show prevention as a key instrument, may help clinicians understand the trends of health demands of the ageing population and therefore improve patient satisfaction with their care.

Our study reports some important associations of PT with exercise, prevention, and movement, especially from the 2000-2004 quinquennium onwards. The change of the scientific perspective concurs with the active ageing definition publication by the World Health Organization in 2002. The definition refers to active ageing as the generation of healthy lifestyles, which are multidimensional and promote health but also prevent frailty and provide longevity and a good functional status [59]. Therefore, in the last quinquennium, there was a superabundance of terms and co-occurrences among keywords implying the prevention of diseases and disorders of the elderly and the improvement of their quality of life. In fact, there are recent studies that focus on how to prevent age-related physical fitness decline even in the aged working population. Representatives of certain professions, such as police officers, need minimum physical standards to perform their jobs and, therefore, a regular training programme is required as they get older [60]. The productivity trends shown in our study highlight the fact that clinicians have more evidence on which to base their decisions when preventing age-related physical changes.

On the other hand, links with keywords such as fall, stroke, osteoarthritis, or surgery ascertain that, as in other geriatric studies [61], research on PT in ageing is also related to aspects of the most common pathologies among the elderly, such as cerebrovascular disease, arthritis, or coronary artery disease [62].

From the $2^{\text {nd }}$ quinquennium (1995-1999) onwards, keywords related to scientific research, such as clinical trial, scale, reliability, follow-up, or outcome, were consolidating and increasing. This reveals a greater interest of PT in ageing towards research [39] and concurs with the rise of the concept of evidence-based practice in the early 1990s, marked by the founding of the Cochrane Collaboration in 1993. Moreover, our results show that research methods evolved toward higher designs. As Wiles et al. [23] highlight in their study, this research evolution is necessary to underpin treatment decision making, which subsequently informs the provision of effective and resource-efficient health services.

Regarding authors and institutions, our results facilitate, on the one hand, choosing, on the basis of science, where to focus both human and financial resources [31, 63]; on the other hand, they may improve contact and promotion of research groups so that innovative projects can be developed based on interdisciplinary collaboration agreements $[64,65]$. In fact, authors' collaboration has improved since there was an increase in the number of signatures per article, which indicates an increase of researchers' participation. This reflects the complexity of and effort involved in integrating the different approaches to the study of ageing. Consequently, there are authors who point out the need for broadening the collaboration of professionals who investigate ageing, thus creating the conditions for multidisciplinary research as a guarantee of future progress [66].

Identifying the main authors of the area is important if one considers that scientific publications become the best presentation of a scientist and allow to obtain a series of advantages, such as promotions, improvement in the academic positions, or prestige [67]. By using Lotka's $\mathrm{PI}$, the 14 highly productive authors of the area have been identified. All of them exhibited increasing productivity percentages throughout the studied period, which indicates that they are consolidated authors in the area. However, a high transience has also been shown since $86.20 \%$ are 'occasional authors,' who only produced an article within the 25 studied years. This aspect has also been observed in other biomedicine studies, which have presented transience indexes above $70 \%$ [68].

In terms of impact, the most productive author is also the most cited one, accumulating the highest number of citations in the period of 2005-2009, as in previous bibliometric studies on PT [21, 22]. Therefore, she is a consolidated author in the area of PT in general and in ageing in particular.

The fact that authors present a low correlation between productivity and citation indicates that they did not adjust to the consideration that for a certain number of published articles they received $n$ citations [69]. However, it does explain that some authors received a high number of citations with few publications. Moreover, since research is a multidimensional process, the $h$-index was also analysed to evaluate the researchers' impact. The $h$-index tends to penalize authors who prioritize quality over quantity [44]. Nevertheless, this has not been observed, since the highly productive authors published a large number of documents and also their contributions exhibited much relevance.

In relation to institutions, there is a high percentage of articles with only one signing institution, while in smaller percentages, 2, 3, or 4 institutions collaborated. This could indicate that the research in PT in ageing is not usually of a multicentre type, although a more exhaustive analysis through collaborative networks will be addressed in future lines of investigation.

The 5 most productive institutions were all universities and were included in the Academic Ranking of World Universities (ARWU) 2018. As Wiles et al. [23] point out, productivity in PT has changed since 1945 , when only $22.2 \%$ of the author affiliations were to educational or research institutions: in 2010, the percentage of this type of institution equalled $69.6 \%$. Taking into account this general evolution of PT, our results, and the arousing interest of universities and governments throughout the world on ARWU, the increase in the quality of PT publications on ageing is evident.

With reference to countries, in absolute terms, scientific production was led by the United States and followed the pattern of other ageing studies [53] and other bibliometric studies of different scientific areas [36, 37]. In terms of productivity, the United States were followed by other developed countries, such as the United Kingdom, Australia, Canada, or Germany, as in other biomedicine or health sciences bibliometric studies [70, 71]. All of these countries are well represented and consolidated in WCPT [23], which promotes and supports PT research.

Australia was among the 3 most productive countries, both in absolute terms and in relation to GDP and the ageing population, and it was the country of the 3 most productive institutions. In 2001, the Ministry for Ageing of Australia established a series of lines of action for ageing. These included more research in order to guide policies development, establish priorities for future action, and evaluate the impact of policies, programmes, and services, guiding individual and social action, with special emphasis on research related to healthy ageing [72]. This fact makes it clear that research support from governmental policies is very important for high quality scientific productivity.

Some authors point out that the demographic change that ageing implies is a planetary process that has not yet finished because ageing is not homogeneous in all countries [73, 74]. Moreover, in many developed and developing countries, 
PT is underfunded, underestimated, and understaffed [75]. Therefore, global, advanced, diversified and specialized research on ageing in all developing countries is encouraged [54]. Despite these worldwide guidelines to increase research on ageing both in developed and developing countries, our results show a significant and positive correlation between GDP and scientific productivity $(p<0.01)$. This implies higher productivity of countries with a wealthier position [70, 71], and thus developed countries are consolidated as ones with influence and repercussion of PT in ageing research.

On the other hand, productivity in relation to population ageing shows that Sweden was the country in the first position. Sweden was among the first nations to experience a rapid ageing of the population [76] and therefore it has a longer history in gerontological research when compared with other countries [77]. The United States, United Kingdom, Canada, or Germany, with an outstanding situation in absolute productivity terms, had a lower position in productivity related to their populations' ageing. In fact, the correlation between productivity and population ageing is very low $(p>$ 0.01 ) and thus Japan, the country with the highest proportion of the population over 65 years and with higher life expectancy [78], does not appear among the 10 most productive or most cited, although this may also be due to a linguistic bias [71].

Regarding institutions and countries citations, they were both led by the United States. Considering that in the United States, the granting of subsidies to institutions is based on the evaluation of results and number of citations of their publications [79-81], this may be explained. Moreover, the correlation between productivity and citation for both institutions and countries was positive, significant, and high or very high, respectively. That is, as institutions and countries become more productive, the number of citations increases, aspect that can encourage PT researchers in ageing to collaborate with certain institutions.

\section{Limitations}

The current study is not exempt from limitations: (a) Only choosing the SCI-E of WoS Core Collection database restricted the inclusion of journals indexed elsewhere. (b) Furthermore, there were often problems of quality in the bibliographic data. These issues are important when analysing authorship, either because the authors themselves do not always sign the papers in the same way or because of errors at the time of processing the information. To minimize this problem, a careful manual check was carried out to unify different variations in the names of particular authors or institutions.

Given that ageing is related to social aspects, one of the future lines of research is to expand the search in the Social Sciences Citation Index. It would also be interesting to analyse other databases, such as Scopus or PEDro.

\section{Conclusions}

The findings of this bibliometric study show an exponential increase in productivity of PT in ageing research over the period 1990-2014, which indicates the consolidation of the discipline. Initially, topics were related to the treatment of pathologies, while at the end of the 25-year period, trends reveal a change of paradigm, with articles focused on prevention and quality of life improvement in the aged population. Publishing authors and institutions of the area increased, as well as their citation and impact. As for the countries, the United States were the leader in terms of absolute produc- tivity, Australia had 3 of the main publishing institutions, and Sweden was the most productive in relation to ageing of the population and also to GDP. Moreover, the correlation analysis of the bibliometric and socioeconomic indicators has demonstrated a significant relationship between productivity and the wealth of the countries, but not between productivity and the ageing of their populations.

All this information makes it possible to clearly observe the evolution of scientific research and to consider where to aim in future studies, on the basis of the concerns and deficiencies of the profession. Describing the publication patterns of PT in ageing over the presented 25-year period allows inferences about the evolution of this speciality.

\section{Funding}

The authors state that there are no funding sources related to this article.

\section{Disclosure statement}

No author has any financial interest or received any financial benefit from this research.

\section{Conflict of interest}

The authors state no conflict of interest.

\section{References}

1. United Nations, Department of Economic and Social Affairs. World population prospects: the 2017 revision. 2017. Available from: https://www.un.org/development/ desa/publications/world-population-prospects-the2017-revision.html [January 2018].

2. Instituto de Mayores y Servicios Sociales (IMSERSO). 2016 report. The elderly in Spain. Statistical data by state and autonomous community [in Spanish]. Madrid: Ministerio de Sanidad, Servicios Sociales e Igualdad; 2016. Available from: https://www.imserso.es/InterPresent1/ groups/imserso/documents/binario/112017001_informe-2016-persona.pdf [January 2018].

3. World Health Organization. Global health estimates 2013: deaths by cause, age, sex and regional grouping, 20002012. Geneva: World Health Organization; 2015.

4. Abrahin O, Rodrigues RP, Nascimento VC, Da SilvaGrigoletto ME, Sousa EC, Marçal AC. Single- and multiple-set resistance training improves skeletal and respiratory muscle strength in elderly women. Clin Interv Aging. 2014;9:1775-1782; doi: 10.2147/CIA.S68529.

5. Rowe JW, Kahn RL. Successful aging. Gerontologist. 1997;37(4):433-440; doi: 10.1093/geront/37.4.433.

6. Ferdows NB, Jensen GA, Tarraf W. Healthy aging after age 65: a life-span health production function approach. ResAging.2018;40(5):480-507; doi:10.1177/01640275 17713312

7. Gopinath B, Kifley A, Flood VM, Mitchell P. Physical activity as a determinant of successful aging over ten years. Sci Rep. 2018;8(1):10522; doi: 10.1038/s41598-01828526-3.

8. World Confederation for Physical Therapy. WCPT guideline for physical therapist professional entry level education. London: WCPT; 2011. Available from: http:// www.aefi.net/Portals/1/Repository/Guideline_PTEducation_complete.1481e4b7-e059-464a-9ac4-cadf8021d594.pdf [February 2018].

9. Lauretani F, Russo CR, Bandinelli S, Bartali B, Cavazzini C, Di lorio A, et al. Age-associated changes in skeletal muscles and their effect on mobility: an operational diagnosis of sarcopenia. J Appl Physiol. 2003;95(5):18511860; doi: 10.1152/japplphysiol.00246.2003. 
10. Maher CG, Moseley AM, Sherrington C, Elkins MR, Herbert RD. A description of the trials, reviews, and practice guidelines indexed in the PEDro database. Phys Ther. 2008;88(9):1068-1077; doi: 10.2522/ptj.20080002.

11. Moseley AM, Herbert RD, Sherrington C, Maher CG. Evidence for physiotherapy practice: a survey of the Physiotherapy Evidence Database (PEDro). Aust J Physiother. 2002;48(1):43-49; doi: 10.1016/s0004-9514(14) 60281-6.

12. Dean E, Davies J. Frequency of citation and reputational assessment of contributors in physical therapy. Phys Ther. 1986;66(6):961-966; doi: 10.1093/ptj/66.6.961.

13. Bohannon RW, Gibson DF. Citation analysis of Physical Therapy. Aspecial communication. Phys Ther. 1986;66(4): 540-541; doi: 10.1093/pti/66.4.540.

14. Pena Costa LO, Moseley AM, Sherrington C, Maher CG, Herbert RD, Elkins MR. Core journals that publish clinical trials of physical therapy interventions. Phys Ther. 2010;90(11):1631-1640; doi: 10.2522/ptj.20090419.

15. Maher CG, Moseley AM, Sherrington C, Herbert RD. Core journals of evidence-based physiotherapy practice. Physiother Theory Pract. 2001;17(3):143-151; doi: 10.1080/095939801317077605.

16. Moseley AM, Herbert RD, Maher CG, Sherrington C, Elkins MR. Reported quality of randomized controlled trials of physiotherapy interventions has improved over time. J Clin Epidemiol. 2011;64(6):594-601; doi: 10.1016/ j.jclinepi.2010.08.009.

17. Bohannon RW, Roberts D. Core journals of rehabilitation: identification through index analysis. Int J Rehabil Res. 1991;14(4):333-335.

18. Tesio L, Gamba C, Capelli A, Franchignoni FP. Rehabilitation: the Cinderella of neurological research? A bibliometric study. Ital J Neurol Sci. 1995;16(7):473-477; doi: 10.1007/BF02229325.

19. Lankhorst GJ, Franchignoni F. The 'impact factor' - an explanation and its application to rehabilitation journals. Clin Rehabil. 2001;15(2):115-118; doi: 10.1191/026921 501676657944.

20. Maher CG, Sherrington C, Elkins M, Herbert RD, Moseley AM. Challenges for evidence-based physical therapy: accessing and interpreting high-quality evidence on therapy. Phys Ther. 2004;84(7):644-654; doi: 10.1093/ ptj/84.7.644.

21. Coronado RA, Wurtzel WA, Simon CB, Riddle DL, George SZ. Content and bibliometric analysis of articles published in the Journal of Orthopaedic \& Sports Physical Therapy. J Orthop Sports Phys Ther. 2011;41(12): 920-931; doi: 10.2519/jospt.2011.3808.

22. Coronado RA, Riddle DL, Wurtzel WA, George SZ. Bibliometric analysis of articles published from 1980 to 2009 in Physical Therapy, journal of the American Physical Therapy Association. Phys Ther. 2011;91(5):642-655; doi: 10.2522/ptj.20100267.

23. Wiles L, Matricciani L, Williams M, Olds T. Sixty-five years of Physical Therapy: bibliometric analysis of research publications from 1945 through 2010. Phys Ther. 2012; 92(4):493-506; doi: 10.2522/ptj.20110013.

24. Svien L, Anderson S, Long T. Research in pediatric physical therapy: an analysis of trends in first fifteen years of publication. Pediatr Phys Ther. 2006;18(2):126-132; doi: 10.1097/01.pep.0000223104.28243.5e.

25. Hoffmann T, Bennett S, McKenna K, Green-Hill J, McCluskey A, Tooth L. Interventions for stroke rehabilitation: analysis of the research contained in the OTseeker evi- dence database. Top Stroke Rehabil. 2008;15(4):341350; doi: 10.1310/tsr1504-341.

26. Elsner B. Systematic reviews for informing clinical practice. Physiother Res Int. 2018;23(1):e1703; doi: 10.1002/ pri.1703.

27. Snell K, Hassan A, Sutherland L, Chau L, Senior T, Janaudis-Ferreira $T$, et al. Types and quality of physical therapy research publications: has there been a change in the past decade? Physiother Can. 2014;66(4):382-391; doi: 10.3138/ptc.2013-67.

28. Fernández JL, Parapar C, Ruiz M. Population ageing [in Spanish]. Lychnos. 2010;2:6-11.

29. Boyack KW, Klavans R. Creation of a highly detailed, dynamic, global model and map of science. J Assoc Inf Sci Technol. 2014;65(4):670-685; doi: 10.1002/asi.22990.

30. Huang $M-H$, Chang C-P. Detecting research fronts in OLED field using bibliographic coupling with sliding window. Scientometrics. 2014;98:1721-1744; doi: 10.1007/ s11192-013-1126-1.

31. Glänzel W, Debackere K. On the opportunities and limitations in using bibliometric indicators in a policy relevant context. In: Bibliometric analysis in science and research: applications, benefits and limitations. Jülich: Forschungszentrum Jülich; 2003; 225-236.

32. Tilson JK, Marshall K, Tam JJ, Fetters L. A bibliometric analysis of statistical terms used in American Physical Therapy Association journals (2011-2012): evidence for educating physical therapists. BMC Med Educ. 2016; 16:118; doi: 10.1186/s12909-016-0641-1.

33. Yuan $Y$, Gretzel U, Tseng $Y-H$. Revealing the nature of contemporary tourism research: extracting common subject areas through bibliographic coupling. Int J Tour Res. 2015;17(5):417-431; doi: 10.1002/jtr.2004.

34. Aleixandre-Benavent R, González-Alcaide G, MiguelDasit A, Navarro-Molina C, Valderrama-Zurián JC. Fulltext publications in peer-reviewed journals derived from presentations at three ISSI conferences. Scientometrics. 2009;80(2):409-420; doi: 10.1007/s11192-008-2066-z.

35. Aleixandre JL, Aleixandre-Tudó JL, Bolaños-Pizzaro M, Aleixandre-Benavent R. Mapping the scientific research on wine and health (2001-2011). J Agric Food Chem. 2013;61(49):11871-11880; doi: 10.1021/jf404394e.

36. Aleixandre-Benavent R, Alonso-Arroyo A, Chorro-Gascó FJ, Alfonso-Manterola F, González-Alcaide G, Salvador-Taboada MJ, et al. Cardiovascular scientific production in Spain and in the European and global context (2003-2007) [in Spanish]. Rev Esp Cardiol. 2009;62(12): 1404-1417; doi: 10.1016/S0300-8932(09)73126-4.

37. National Center for Biotechnology Information. Medical subject headings. Available from: https://www.ncbi. nlm.nih.gov/mesh/ [November 2015].

38. De Freitas AE, Herbert RD, Latimer J, Ferreira PH. Searching the LILACS database for Portuguese- and Spanishlanguage randomized trials in physiotherapy was difficult. J Clin Epidemiol. 2005;58(3):233-237; doi: 10.1016/j. jclinepi.2004.06.014.

39. García Ríos MC, Moreno Lorenzo C, Ruiz Baños R, Bailón Moreno R. Thematic analysis of the discipline of physiotherapy in the Web of Science [in Spanish]. Fisioterapia. 2010;32(4):159-164; doi: 10.1016/j.tt.2009.09.004.

40. Wakiji EM. Mapping the literature of physical therapy. Bull Med Libr Assoc. 1997;85(3):284-288.

41. World Confederation for Physical Therapy. WCPT glossary: terms used in WCPT's policies and resources. London: WCPT; 2014. 
42. Thompson DF, Walker CK. A descriptive and historical review of bibliometrics with applications to medical sciences. Pharmacotherapy. 2015;35(6):551-559; doi: 10.1002/phar.1586.

43. Hirsch JE. An index to quantify an individual's scientific research output. Proc Natl Acad Sci USA. 2005;102(46): 16569-16572; doi: 10.1073/pnas.0507655102.

44. Ardanuy J. A brief introduction to bibliometrics [in Spanish]. Barcelona: Universitat de Barcelona, Departament de Biblioteconomia i Documentació; 2012.

45. Jesus TS. Systematic reviews and clinical trials in rehabilitation: comprehensive analyses of publication trends. Arch Phys Med Rehabil. 2016;97(11):1853-1862.e2; doi: 10.1016/j.apmr.2016.06.017.

46. Kocak FU, Unver B, Karatosun V. Level of evidence in four selected rehabilitation journals. Arch Phys Med Rehabil. 2011;92(2):299-303; doi: 10.1016/j.apmr.2010. 07.233 .

47. Sturmer G, Viero CCM, Silveira MN, Lukrafka JL, Plentz RDM. Profile and scientific output analysis of physical therapy researchers with research productivity fellowship from the Brazilian National Council for Scientific and Technological Development. Braz J Phys Ther. 2013;17(1):41-48; doi: 10.1590/s1413-355520120050 00068.

48. Vernaza-Pinzón P, Álvarez-Bravo G. Latin American scientific output in physical therapy/kinesiology [in Spanish]. Aquichan. 2011;11(1):94-107; doi: 10.5294/1820.

49. Miller PA, McKibbon KA, Haynes RB. A quantitative analysis of research publications in physical therapy journals. Phys Ther. 2003;83(2):123-131; doi: 10.1093/ptj/ 83.2.123.

50. Mogil JS, Simmonds K, Simmonds MJ. Pain research from 1975 to 2007: a categorical and bibliometric meta-trend analysis of every research paper published in the journal, Pain. Pain. 2009;142(1-2):48-58; doi: 10.1016/j.pain.2008.11.012.

51. Smith DR, Rivett DA. Bibliometrics, impact factors and manual therapy: balancing the science and the art. Man Ther. 2009;14(4):456-459; doi: 10.1016/j.math.2008. 11.004 .

52. De Miguel Antón JL, Fernández Nuevo JL, Parapar Barrera C, Ruiz Yaniz M. Research on ageing [in Spanish]. Madrid: Fundación General CSIC; 2016. Available from: http://envejecimiento.csic.es/documentos/documentos/Informeinvestigacionenvejecimiento2017.pdf [March 2018].

53. Parapar Barrera C, Fernández Nuevo JL, Rey Campos J, Ruiz Yaniz M. I+D+i report on ageing [in Spanish]. Madrid: Fundación General CSIC; 2010. Available from: http://www.fgcsic.es/files/adjuntos/InformeEnvejecimiento.pdf [March 2018].

54. Research agenda on ageing for the $21^{\text {st }}$ century: 2007 update. New York: United Nations Programme on Ageing, International Association of Gerontology and Geriatrics; 2007. Available from: https://www.un.org/esa/ socdev/ageing/documents/AgeingResearchAgenda-6. pdf [March 2018].

55. Harmell AL, Jeste D, Depp C. Strategies for successful aging: a research update. Curr Psychiatry Rep. 2014; 16(10):476; doi: 10.1007/s11920-014-0476-6.

56. Pruchno R, Carr D. Successful aging 2.0: resilience and beyond. J Gerontol B Psychol Sci Soc Sci. 2017;72(2): 201-203; doi: 10.1093/geronb/gbw214.

57. Mazurek J, Sutkowska E, Szcześniak D, Urbańska KM, Rymaszewska J. FIMA, the questionnaire for health-re- lated resource use in the elderly population: validity, reliability, and usage of the Polish version in clinical practice. Clin Interv Aging. 2018;13:787-795; doi: 10.2147/ CIA.S158951.

58. Seidl H, Bowles D, Bock J-O, Brettschneider C, Greiner W, König $\mathrm{H}-\mathrm{H}$, et al. FIMA - questionnaire for health-related resource use in an elderly population: development and pilot study [in German]. Gesundheitswesen. 2015;77(1): 46-52; doi: 10.1055/s-0034-1372618.

59. Organización Mundial de la Salud. Active ageing: a political framework [in Spanish]. Rev Esp Geriatr Gerontol. 2002;37(Suppl. 2):74-105.

60. Teixeira J, Monteiro L, Silvestre R, Beckert J, Massuça LM. Age-related influence on physical fitness and individual on-duty task performance of Portuguese male non-elite police officers. Biol Sport. 2019;36(2):163-170; doi: 10.5114/biolsport.2019.83506.

61. Ribera Casado JM. Investigation in aging today. Principal health challenges. Perspective from geriatrics [in Spanish]. Rev Esp Geriatr Gerontol. 2001;36(Suppl. 3):7-12.

62. World Health Organization. Study on global ageing and adult health (SAGE). Geneva: WHO. 2006. Available from: https://www.who.int/healthinfo/survey/SAGESurveyManualFinal.pdf.

63. Garfield E, Welljams-Dorof A. Citation data: their use as quantitative indicator for science and technology evaluation and policy-making. Sci Public Policy. 1992;19(5): 321-327; doi: 10.1093/spp/19.5.321.

64. González de Dios J, Aleixandre Benavent R. Evaluation of research in biomedicine and health sciences: bibliometric and cybermetric indicators [in Spanish]. Bol Pediatr. 2007;47:92-110.

65. Long JC, Cunningham FC, Carswell P, Braithwaite J. Patterns of collaboration in complex networks: the example of a translational research network. BMC Health Serv Res. 2014;14:225; doi: 10.1186/1472-6963-14-225.

66. Rodríguez Rodríguez V, Rodríguez Mañas L, Sancho Castiello M, Díaz Martín R. Ageing: research in Spain and Europe [in Spanish]. Rev Esp Geriatr Gerontol. 2012; 47(4):174-179.

67. Fenning TM. Fraud offers big rewards for relatively little risk. Nature. 2004;427(6973):393; doi: 10.1038/427393a.

68. López-Muñoz F, Alamo C, Rubio G, García-García P, Martín-Agueda B, Cuenca E. Bibliometric analysis of biomedical publications on SSRI during 1980-2000. Depress Anxiety. 2003;18(2):95-103; doi: 10.1002/da.10121.

69. Melero Fuentes D. Analysis of the scientific output on addictive substances in the Web of Science in the period of 2008-2012 [in Spanish]. Valencia: Universidad Católica de Valencia San Vicente Mártir; 2016.

70. González Block MA. The state of international collaboration for health systems research: what do publications tell? Health Res Policy Syst. 2006;4:7; doi: 10.1186/ 1478-4505-4-7.

71. Soteriades ES, Rosmarakis ES, Paraschakis K, Falagas ME. Research contribution of different world regions in the top 50 biomedical journals (1995-2002). FASEB J. 2006;20(1):29-34; doi: 10.1096/fj.05-4711lsf.

72. Andrews K. National strategy for an ageing Australia. Canberra: Department of Health and Ageing; 2001. Available from: https://ifa.ngo/wp-content/uploads/2012/11/ 062_Australia-2001-National-Strategy-for-an-AgeingAustralia.pdf [March 2018].

73. Pérez J, Abellán A. Ageing societies: a challenge for the $21^{\text {st }}$ century [in Spanish]. Lychnos. 2010;2:46-51. 
74. Podestá O, Risso F. The role of physiotherapists among the elderly [in Spanish]. Rosario: Universidad Abierta Interamericana, Facultad de Medicina y Ciencias de la Salud; 2009.

75. Carmeli E. Physical therapy for neurological conditions in geriatric populations. Front Public Health. 2017;5:333; doi: 10.3389/fpubh.2017.00333.

76. Sundström G. Demography of aging in the Nordic countries. In: Uhlenberg P (ed.), International handbook of population aging. Dordrecht: Springer; 2009; 91-111.

77. Davey A, Malmberg B, Sundström G. Aging in Sweden: local variation, local control. Gerontologist. 2014;54(4): 525-532; doi: 10.1093/geront/gnt124.

78. World Health Organization. The top 10 causes of death. 2020. Available from: http://www.who.int/mediacentre/ factsheets/fs310/en/index.html [March 2018].

79. Borgman CL, Furner J. Scholarly communication and bibliometrics. Annu Rev Inform Sci Technol. 2002;36(1): 3-72; doi: 10.1002/aris.1440360102.

80. Lewison G, Cottrell R, Dixon D. Bibliometric indicators to assist the peer review process in grant decisions. Res Eval. 1999;8(1):47-52; doi: 10.3152/14715449978177 7621.

81. Sharma A, Singh HP, Kaur P, Gupta I. Impact factor: a tool to measure quality of research articles. Int J Appl Res Stud. 2013;2(6):1-4.

\section{Appendix 1}

The final search strategy was as follows:

((“Physical Therap*”) OR (Physiotherap*) OR ((“Physical Therap*" OR Physiotherap*) AND (Modalities OR Specialty OR Assistants))) AND ((Aging OR ageing OR elder* OR Aged OR "grey-headed" OR senior OR senil* OR "old age" OR "old adult" OR "older adults" OR frailty OR "frail elderly" OR geriatric OR pensioner OR "retired person" OR senescence OR gerontology) NOT (pediatric OR child* OR infancy OR adolescen* OR "young adult" OR teen* OR juvenile OR youth*)) AND (((Musculoskeletal OR chiropractic OR vertebral OR spinal OR osteopathic) AND Manipulations) OR (postural AND (control OR balance)) OR ((exercise OR music OR respiratory OR acupuncture OR ("Electric Stimulation") OR ("Animal Assisted") OR myofascial OR ("soft tissue") OR ("articulatory manual") OR manual OR aquatic) AND therapy) OR (exercise AND (test OR ("movement techniques") OR breathing OR aerobic OR program OR ("muscle stretching")) OR ("Integumentary System") OR (((“Public Health Profes- sional") OR Graduate OR Continuing OR Health) AND Education) OR (Research) OR ("Clinical Protocols") OR (Practice AND (Professional OR Guideline OR Evidence-Based OR ("Public Health"))) OR (Health AND (Policy OR Promotion OR ("National Programs"))) OR (Acupuncture) OR ("Hot Temperature") OR (Cryotherapy) OR ("Physical Fitness") OR ((Gait OR Functional OR strength OR balance OR resistance OR endurance) AND training) OR (Hydrotherapy) OR ((Ortho*) AND (procedures OR devices)) OR ("Motor Skills") OR (Sports) OR ("Range Motion, Articular") OR ("Wound Healing") OR (Balneology) OR ("Hyperthermia, Induced") OR ("alternative and complementary medicine") OR (bio-feedback) OR (Massage) OR ((cardiac OR pulmonary OR neurological) AND rehabilitation) OR (home AND (program OR exercises)) OR (mobilization) OR (electrotherapy) OR (hydrotherapy) OR (osteopathy) OR (Stretching) OR ("Trunk muscle strength"))) 